\title{
Pengembangan Media Pembelajaran Sains Berbasis Prezi untuk Siswa Sekolah Dasar pada Materi Penggolongan Hewan
}

\author{
Muharni $^{1}$, Mahmud Alpusari², Zetra Hainul Putra ${ }^{3 *}$ \\ ${ }^{1,3}$ Program Studi Pendidikan Guru Sekolah Dasar, Universitas Riau \\ ${ }^{2}$ Program Studi Pendidikan Guru Sekolah Dasar dan Pendidikan Profesi Guru, Universitas Riau \\ *Correspondence Address: zetra.hainul.putra@lecturer.unri.ac.id
}

\begin{abstract}
This study aims to design and develop Prezi based learning media on animal classification topic. The method used is research and development based on ADDIE model, including analysis, design, develop, implementation, and evaluation. Data were collected through questionnaires. After analyzing curriculum and design Prezi based learning media on animal classification, the research continued into the developmental process. In this step, the media were validated by three experts, namely language, media, and content experts. The results showed Prezi based learning media on animal classification has high validation criteria to be used in learning science in elementary school. Then, Prezi based learning media was tested with 21 third grade students from a private school in Pekanbaru. The results shows that Prezi based learning media have effective in supporting students to learn animal classification, and the students were very motivating and enjoy learning. The implication of this study is that there is high potential for using Prezi based learning media in learning science.
\end{abstract}

Keywords: animal classification, development research, Prezi-based learning.

\begin{abstract}
ABSTRAK
Penelitian ini bertujuan untuk merancang dan mengembangkan media pembelajaran berbasis Prezi pada topik klasifikasi hewan. Metode yang digunakan adalah penelitian dan pengembangan berdasarkan model ADDIE, meliputi analisis, perancangan, pengembangan, implementasi, dan evaluasi. Data dikumpulkan melalui kuesioner. Setelah menganalisis kurikulum dan merancang media pembelajaran berbasis Prezi pada klasifikasi hewan, penelitian dilanjutkan ke proses pengembangan. Pada tahap ini media divalidasi oleh tiga orang ahli yaitu ahli bahasa, ahli media, dan ahli isi. Hasil penelitian menunjukkan media pembelajaran berbasis Prezi klasifikasi hewan memiliki kriteria validasi tinggi untuk digunakan dalam pembelajaran IPA di sekolah dasar. Kemudian media pembelajaran berbasis Prezi diujicobakan kepada 21 siswa kelas III sekolah swasta di Pekanbaru. Hasil penelitian menunjukkan bahwa media pembelajaran berbasis Prezi efektif dalam mendukung siswa dalam belajar klasifikasi hewan, dan siswa sangat memotivasi serta menikmati pembelajaran. Implikasi dari penelitian ini adalah tingginya potensi penggunaan media pembelajaran berbasis Prezi dalam pembelajaran IPA.
\end{abstract}

Kata kunci: penelitian pengembangan, pembelajaran berbasis Prezi.

\section{PENDAHULUAN}

Pembangunan pendidikan merupakan bagian dari pembangunan nasional. Untuk meningkatkan dan memajukan sektor pendidikan, tujuan ini harus dicapai. Penurunan kualitas pendidikan telah menarik perhatian luas dari masyarakat, guru dan pimpinan pendidikan. Oleh karena itu, pemerintah berupaya melakukan pembenahan dan perbaikan di bidang pendidikan. Sebagai 
langkah yang diharapkan, berbagai pendidikan diarahkan untuk membangun proses pembelajaran, menggunakan dan memilih media pembelajaran secara tepat.

Permasalahan yang dihadapi guru adalah bagaimana menciptakan suasana pembelajaran di kelas agar aktif dan menarik, sehingga siswa merasa nyaman dan senang mengikuti pembelajaran. Penggunaan media pembelajaran juga harus disesuaikan dengan minat siswa dalam merespon kemajuan teknologi. Para siswa saat ini sangat menyukai aroma teknologi modern, dan guru harus menggunakannya sebagai media pembelajaran yang baik. Media pembelajaran yang umum digunakan dalam proses pembelajaran adalah media berbasis Powerpoint. Sama seperti penelitian sebelumnya bahwa siswa kelas enam di salah satu Sekolah Dasar di Pekanbaru sangat tertarik menggunakan PowerPoint untuk pembelajaran, dan hasil belajar siswa tersebut juga mengalami peningkatan (Putra et al., 2019). Namun media berbasis Powerpoint memiliki kekurangan yaitu tidak memiliki fungsi zoom, sehingga ukuran gambar yang kecil tidak dapat terlihat dengan jelas. Oleh karena itu, penggunaan media pembelajaran berbasis zoom perlu diterapkan di dalam kelas, salah satunya melalui penggunaan software Prezi (Perron \& Stearns, 2010; Settle et al., 2011).

Prezi merupakan sebuah perangkat lunak untuk presentasi berbasis jaringan Internet (Perron \& Stearns, 2010). Prezi juga bisa dimanfaatkan sebagai media untuk mengeksplorasi dan berbagi ide di atas kanvas virtual. Prezi sangat bagus karena programnya menggunakan "Zoom User Interface" (ZUI) yang memungkinkan pengguna dapat memperbesar dan memperkecil media presentasi yang mereka sajikan (Perron \& Stearns, 2010).

Menurut Harvey dan Barringer (dalam Surani \& Ampera, 2017), Pręi adalah presentasi yang dapat membantu presenter menyampaikan informasi kompleks secara dinamis agar menarik. Prezi juga merupakan perangkat lunak presentasi "berbasis Flash" yang memungkinkan pengguna dengan bebas membuat presentasi dinamis yang terlihat berbeda dari tayangan slide PowerPoint umum. Program Zoom User Interface (ZUI) membuat pembelajaran menjadi menyenangkan dan memvisualisasikan materi yang akan dikomunikasikan. Keunggulan yang diberikan oleh Prezi adalah dapat diakses secara online kapan saja melalui komputer atau ponsel. Faktor ini sangat penting karena dianggap pembelajaran yang dibutuhkan saat ini tidak hanya di dalam kelas, tetapi dapat dilaksanakan secara fleksibel kapanpun dan dimanapun (Burhanudin \& Suyoso, 2018).

Walaupun penelitian sebelumnya telah banyak melakukan penelitian tentang pengembangan media pembelajaran Prezi (Lam, 2014), namun peneliti belum menemukan perkembangan media pembelajaran berbasis Prezi di sekolah dasar. Hal ini menunjukkan bahwa perlu dilakukan penelitian tentang pengembangan media pembelajaran berbasis Prezi di sekolah dasar untuk mendukung peningkatan kualitas pembelajaran. Alasan ini dianggap penting karena sejak sekolah dasar, teknologi yang berkembang harus sesuai dengan penggunaannya di bidang pendidikan. Oleh karena itu, dalam penelitian ini, peneliti memfokuskan pada pengembangan materi penggolongan hewan di kelas tiga sekolah dasar berbasis Prezi. Materi penggolongan hewan dipilih untuk dikembangkan dalam penelitian ini karena pelaksanaan pembelajaran penggolongan hewan dilaksanakan secara konvensional yaitu guru berfokus pada penyampaian materi berdasarkan buku teks dan meminta siswa untuk mengingat penggolongan hewan, misalnya berdasarkan jenis makananya.

Dari latar belakang masalah yang telah diuraikan di atas, maka rumusan masalah dalam penelitian ini adalah "Apakah media pembelajaran berbasis Preæi pada materi penggolongan hewan di kelas tiga sekolah dasar layak digunakan dalam pembelajaran?"

\section{METODOLOGI}

Penelitian ini menggunakan metode Research and Development (R\&D). Penelitian R\&D merupakan metode penelitian yang menekankan pada proses pengembangan dan validasi produk termasuk di bidang pendidikan (Sanjaya, 2013; Sugiyono, 2014). R\&D telah banyak digunakan 
dalam pengembangan-pengembangan media pembelajaran sains baik untuk digunakan di sekolah dasar hingga perguruan tinggi (Anantyarta \& Sholihah, 2020; Jariati \& Yenti, 2020; Putra et al., 2019; Wahyuni \& Ananda, 2021). Dalam penelitian ini peneliti mengembangkan media pembelajaran tentang materi penggolongan hewan. Proses pengembangan menggunakan model ADDIE (Analysis, Design, Development, Implementation, and Evaluation) (Wahyuni \& Ananda, 2021) sebagai model yang dinilai sesuai untuk pengembangan media pembelajaran sains berbasis Preqi.

Dalam pengembangan media pembelajaran berbasis Prezi dengan menggunakan model ADDIE terkait penggolongan hewan, peneliti melaksanakan penelitian hingga tahap implementasi terbatas dan evaluasi dari kegiatan implementasi tersebut. Hal ini sejalan dengan tujuan penelitian pengembangan media pembelajaran berbasis Prezi adalah untuk mengetahui kelayakan penggunaan media pembelajaran berbasis Preqi di sekolah dasar, dan mengetahui sejauh mana media pembelajaran berbasis Prezi ini bisa diterima oleh siswa dan mendorong siswa mempelajari penggolongan hewan yang lebih baik.

Subjek dalam validasi produk adalah ahli media, ahli materi, dan guru kelas tiga sekolah dasar. Sementara itu subjek untuk implementasi media Prezi adalah 21 siswa kelas tiga sekolah dasar di kota Pekanbaru. Objek penelitian adalah media pembelajaran materi penggolongan hewan berbasis Prezi dan 21 siswa sekolah dasar sebagai uji coba terbatas media yang dikembangkan. Pengumpulan data dilakukan pada semester ganjil tahun ajaran 2019/2021.

Teknik pengumpulan data yang digunakan dalam studi pengembangan ini berupa angket. Angket yang digunakan berupa angket validasi dan angket uji coba produk. Lembar validasi diberikan kepada ahli media dan ahli materi untuk mengevaluasi penerapan media yang dikembangkan. Angket uji coba produk diberikan kepada guru kelas untuk mengetahui tanggapan mereka terhadap media yang dikembangkan. Data yang diperoleh dari guru kelas kemudian dianalisis dan disimpulkan. Demikian pula, angket uji coba yang diberikan kepada 21 orang siswa kelas tiga untuk memeriksa tanggapan/respon mereka terhadap media yang sedang dikembangkan.

Teknik analisis data yang digunakan pada penelitian adalah analisis deskriptif yakni dengan menyajikan rata-rata dari setiap aspek penilaian yang terdapat dalam masing-masing aspek pada lembar validasi media pembelajaran berbasis Prezi. Tingkat kelayakan media ditetapkan berdasarkan persentase kriteria kelayakan yang disajikan pada Tabel 1 (Liani et al., 2017).

Tabel 1. Kriteria Kelayakan Analisis Persentase

\begin{tabular}{cc}
\hline Persentase & Keterangan \\
\hline $80,00-100$ & Amat Baik \\
\hline $60,00-79,99$ & Baik \\
\hline $50,00-59,99$ & Cukup \\
\hline $0-49,99$ & Kurang \\
\hline
\end{tabular}

\section{TEMUAN DAN PEMBAHASAN}

Produk yang dihasilkan dari penelitian R\&D ini berupa media pembelajaran berbasis Prezi pada materi penggolongan hewan yang telah divalidasi. Hasil penelitian disajikan berdasarkan tahapan-tahapan penelitian dan pengembangan berdasarkan model ADDIE.

\section{Tahap Analyze}

Tahap awal penelitian adalah tahap analisis. Analisis yang dilakukan dalam penelitian ini adalah analisis kebutuhan yang meliputi analisis materi dan analisis media pembelajaran, serta memperoleh gambaran tentang media pembelajaran yang dibutuhkan oleh guru dan siswa. Analisis 
dilakukan dengan wawancara dengan guru kelas 3 sekolah dasar. Wawancara ini menanyakan media pembelajaran yang biasa digunakan dalam pembelajaran IPA. Hasil wawancara dengan guru kelas III tentang penggunaan media pembelajaran yaitu guru menggunakan media pembelajaran berupa Powerpoint. Dalam wawancara, guru juga menyampaikan permasalahan terkait dengan media pembelajaran yang digunakan, misalnya media pembelajaran yang hanya berbentuk kalimat monoton sehingga siswa kehilangan semangat belajarnya, dan proses pembelajaran masih bergantung pada penjelasan guru (teacher centered).

\section{Tahap Design}

Tahap perancangan dimulai dengan merumuskan tujuan pembelajaran dan membuat garis besar materi penggolongan hewan yang didapat dari berbagai sumber seperti buku dan internet. Tahap analisis dilanjutkan dengan melakukan penelitian pustaka. Penelitian kepustakaan dilakukan dengan mengumpulkan informasi dan referensi terkait materi berdasarkan silabus. Sumber informasi dan referensi media pembelajaran meliputi jurnal, situs resmi situs Prezi dan skripsi.

Pada tahap desain juga dilakukan pemilihan slide dan background yang tepat dengan materi penggolongan hewan serta penempatan gambar yang sesuai dengan materi. Untuk pemilihan slide dan background, maka yang dibuat akun Prezi agar dapat log in kedalam sistem tersebut. Tahap desain selanjutnya adalah membuat lembar validasi. Bentuk validasi ada dua, yaitu validasi media dan validasi materi. Gambar 1 menyajikan rancangan awal media pembelajaran penggolongan hewan berbasis Prezi.

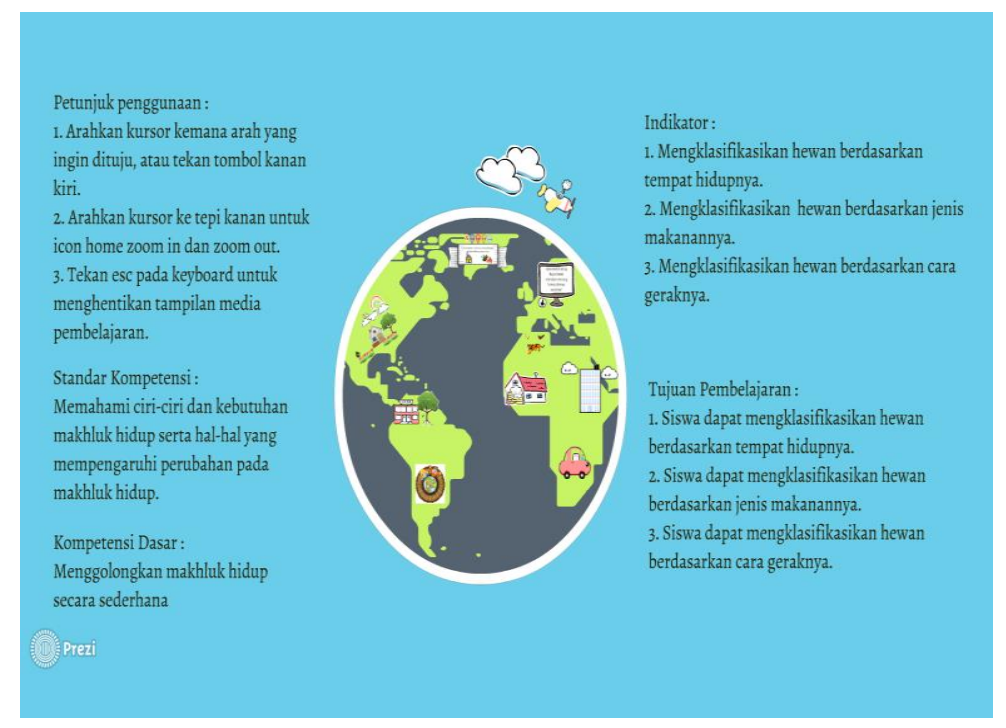

Gambar 1. Tampilan Awal Materi di Prezi

\section{Tahap Development}

Tahap pengembangan yaitu tahap pelaksanaan produksi pembuatan media pembelajaran. Tahap pengembangan berisi kegiatan realisasi rancangan media pembelajaran penggolongan hewan berbasis Prezi. Produk awal yang telah dikembangkan dilakukan penilaian oleh ahli materi dan ahli media untuk mengetahui kelayakan produk yang dikembangkan. Hasil tersebut digunakan dalam proses perbaikan terhadap media pembelajaran Prezi pada materi penggolongan hewan. Setelah ahli materi dan ahli media memvalidasi produk, maka peneliti melakukan perbaikan. Proses perbaikan berlangsung hingga peneliti mendapatkan produk yang dianggap valid dan layak untuk diujicobakan menurut ahli materi dan ahli media.

Media pembelajaran yang telah dikembangkan divalidasi oleh 3 validator yang terdiri dari 1 ahli kebahasaan, 1 ahli media dan 1 ahli materi. Data dari hasil validasi kelayakan dijadikan pedoman untuk revisi media dan uji coba secara terbatas. 
Ahli bahasa dalam penelitian ini merupakan dosen bahasa di jurusan ilmu pendidikan. Hasil penilaiannya adalah bahasa yang digunakan dalam media pembelajaran penggolongan hewan layak digunakan di pembelajaran di kelas 3 sekolah dasar.

Ahli media memberikan tanggapan bahwa media pembelajaran penggolongan hewan yang dikembangkan sudah sesuai dengan materi pembelajaran di kelas 3 sekolah dasar berdasarkan 3 aspek penilaian yang diberikan yaitu aspek perancangan media (91,6\%), aspek tampilan media $(89,2 \%)$ dan aspek pemograman media $(95,4 \%)$. Saran perbaikan yaitu media perlu dilengkapi dengan video yang menunjang pembelajaran. Gambar 2 berikut ini menyajikan contoh hasil perbaikan media sesuai dengan saran ahli media yaitu dengan menambahkan video hewan gajah sedang memakan tumbuhan.

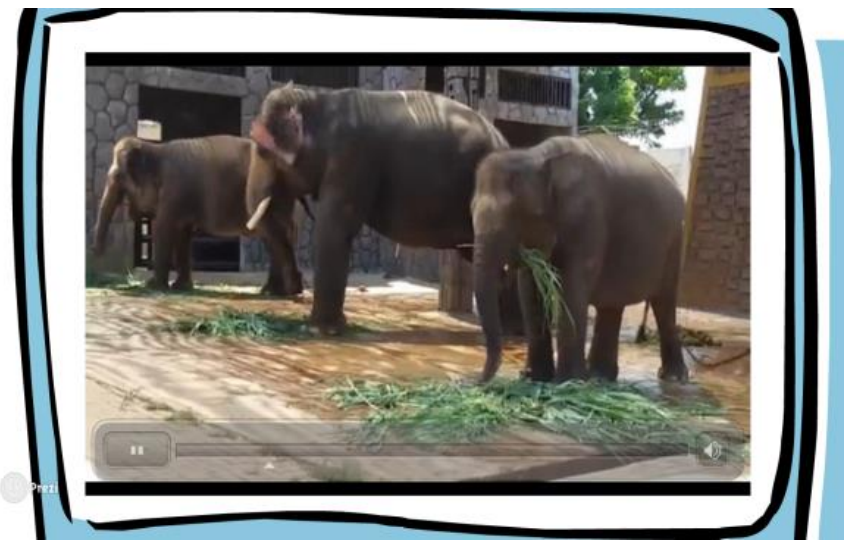

Gambar 2. Tampilan Video Hewan Makan Tumbuhan (Gaming, 2017)

Penilaian ahli materi terhadap media pembelajaran penggolongan hewan menggunakan Prezi juga berada pada kategori layak digunakan dalam pembelajaran di kelas 3 sekolah dasar berdasarkan 6 aspek penilaian. Aspek penilaian kesesuaian dengan tujuan yang harus dicapai memperoleh persentase $90 \%$. Aspek unsur desain pesan bertujuan untuk menilai seberapa besar informasi dalam media dapat dipahami memperoleh persentase 87,5\%. Aspek efektivitas penggunaan media dalam proses pembelajaran memperoleh persentase $90 \%$. Mengacu pada tabel 1, kriteria kelayakan analisis persentase $90 \%$. Aspek kelengkapan materi dalam media pembelajaran berbasis Prezi memperoleh persentase 100\%. Aspek keterbacaan atau ketepatan penggunaan istilah dan gambar dalam media pembelajaran berbasis Prezi juga memperoleh persentase $100 \%$, dan terakhir aspek pedagogik atau kesesuaian dengan karakteristik siswa dalam menggunakan media pembelajaran berbasis Prezi memperoleh persentase 87,5\%. Adapun saran utama ahli materi yaitu terkait perlunya penyesuaian makanan pada hewan ayam yaitu berupa cacing.

\section{Tahap Implementation}

Setelah melakukan revisi terhadap media pembelajaran yang dikembangkan, maka langkah selanjutnya adalah mengujicobakan media pembelajaran penggolongan hewan berbasis Prezi kepada siswa kelas 3 sekolah dasar. Dalam hal ini, peneliti melakukan ujicoba dengan 21 orang siswa kelas 3 dari sebuah sekolah dasar swasta di kota Pekanbaru. Selain itu, peneliti juga meminta saran-saran guru terhadap media pembelajaran penggolongan hewan berbasis Prezi yang telah dikembangkan.

\section{Tahap Evaluation}

Evaluasi terhadap media Prezi yang dikembangkan dilakukan dengan cara meminta siswa memberikan tanggapan terhadap media yang dikembangkan. Siswa mengisi angket yang berjumlah 10 pernyataan. Hasil angket disajikan pada Tabel 2 berikut ini. 
Tabel 2. Penilaian Respon Siswa Kelas 3 Sekolah Dasar

\begin{tabular}{|c|c|c|c|c|}
\hline No & Indikator & Peryataan & Persentase & Kategori \\
\hline 1. & $\begin{array}{l}\text { Efektivitas pembelajaran } \\
\text { menggunakan media pembelajaran }\end{array}$ & $\begin{array}{l}\text { Belajar menggunakan media } \\
\text { pembelajaran berbasis Prezi } \\
\text { sangat menyenangkan. }\end{array}$ & $100 \%$ & Amat Baik \\
\hline 2. & & $\begin{array}{l}\text { Penjelasan yang disampaikan } \\
\text { guru pada media pembelajaran } \\
\text { berbasis Prezi } \\
\text { dimengerti. }\end{array}$ & $100 \%$ & Amat Baik \\
\hline 3. & Efektivitas penyusunan materi & $\begin{array}{l}\text { Materi yang dijelaskan media } \\
\text { pembelajaran berbasis Prezi } \\
\text { cukup jelas. }\end{array}$ & $95,2 \%$ & Amat Baik \\
\hline 4. & & $\begin{array}{l}\text { Materi yang disajikan } \\
\text { menggunakan media } \\
\text { pembelajaran berbasis Prezi } \\
\text { mudah dimengerti. }\end{array}$ & $100 \%$ & Amat Baik \\
\hline 5. & & $\begin{array}{l}\text { Kalimat yang terdapat dalam } \\
\text { media pembelajaran berbasis } \\
\text { Prezi mudah dipahami. }\end{array}$ & $90,4 \%$ & Amat baik \\
\hline 6. & & $\begin{array}{l}\text { Contoh dari setiap materi } \\
\text { yang disajikan dengan media } \\
\text { pembelajaran berbasis Prezi } \\
\text { lengkap dan mudah } \\
\text { dipahami. }\end{array}$ & $85,7 \%$ & Amat baik \\
\hline 7. & $\begin{array}{l}\text { Efektivitas komponen pendukung } \\
\text { media pembelajaran }\end{array}$ & $\begin{array}{l}\text { Tulisan yang ditampilkan } \\
\text { pada media pembelajaran } \\
\text { berbasis Preqi jelas dan } \\
\text { mudah dibaca. }\end{array}$ & $95,2 \%$ & Amat baik \\
\hline 8. & & $\begin{array}{l}\text { Gambar yang ditampilkan } \\
\text { pada media pembelajaran } \\
\text { berbasis Prezi terlihat dengan } \\
\text { jelas. }\end{array}$ & $95,2 \%$ & Amat baik \\
\hline 9. & & $\begin{array}{l}\text { Audio (sound dan background) } \\
\text { yang digunakan pada media } \\
\text { pembelajaran Prezi sudah } \\
\text { tepat dan tidak mengganggu }\end{array}$ & $85,7 \%$ & Amat baik \\
\hline 10. & & $\begin{array}{l}\text { Warna background menarik } \\
\text { dan tidak membuat mata } \\
\text { lelah. }\end{array}$ & $80,9 \%$ & Amat baik \\
\hline
\end{tabular}

Siswa merespon dengan amat baik terhadap media yang telah dikembangkan dengan perolehan rata-rata persentase dari indikator efektivitas pembelalajaran menggunakan media pembelajaran 100\% kategori amat baik, indikator efektivitas penyusunan materi 92,8\% kategori amat baik dan indikator efektivitas komponen pendukung dalam media pembelajaran 89,2\% kategori amat baik. Dari respon yang diberikan siswa terhadap media pembelajaran berbasis Prezi yang dikembangkan, siswa sangat senang belajar menggunakan media tersebut, materi yang disajikan dan dijelaskan oleh guru juga menjadi mudah dimengerti. Namun ada beberapa siswa yang tidak setuju mengenai contoh yang disajikan, tulisan pada media, warna background dan sound, serta kalimat dalam media. Mereka memberikan alasan yaitu mengenai contoh baiknya dibanyakkan dan dibesarkan ukuran gambarnya. Mengenai tulisan dan kalimat, hurufnya kurang besar dan kalimatnya panjang-panjang. Serta mengenai warna background dan sound, ada yang memberikan saran untuk menggunakan warna merah muda, biru, dan kuning serta menggunakan musik pada tayangan upin dan ipin. 


\section{PEMBAHASAN}

Penelitian pengembangan media pembelajaran penggolongan hewan berbasis Preqi dikembangkan dengan menggunakan model ADDIE. Melalu langkah-langkah penelitian pengembangan model ADDIE diperoleh media pembelajaran penggolongan hewan berbasis Prezi yang layak untuk digunakan di kelas 3 sekolah dasar. Hasil ini ditunjukkan dengan penilain ahli bahasa, media, dan materi serta hasil evaluasi siswa terhadap media pembelajaran hewan berbasis Prezi. Hasil penelitian ini mendukung penelitian-penelitian sebelumnya yang menunjukkan bahwa media pembelajaran berbasis Prezi memiliki potensi yang baik untuk dikembangkan dan digunakan dalam pembelajaran sains (Mahyuddin et al., 2017; Rodhi \& Wasis, 2014; Untari et al., 2014). Pengembangkan media pembelajaran Pręi pada materi kalor yang memenuhi kriteria kelayakan untuk digunakan baik dari segi tampilan maupun materi yang disajikan (Rodhi \& Wasis, 2014).

Kelayakan media pembelajaran penggolongan hewan menggunakan Prezi ini juga ditunjukkan oleh respon siswa ketika dilaksanakan uji coba di kelas. Siswa sangat antusias dan senang ketika mengikuti pembelajaran menggunakan media pembelajaran berbasis Prezi ini. Hasil ini dditunjukkan dengan persentase respon siswa yang sangat baik terhadap media Prezi yang dikembangkan. Selain itu, mereka mengatakan bahwa mereka dapat dengan mudah mengerti materi yang disajikan dengan menggunakan media pembelajaran berbasis Prezi. Hal ini sejalan dengan pendapat Hamalik (dalam Azhar, 2011) yang mengatakan bahwa media pembelajaran dapat meningkatkan keinginan dan minat, membangun motivasi dan rangsangan belajar, dan juga memberikan pengaruh-pengaruh psikologis yang baik terhadap peserta didik. Sementara itu, hasil penelitian ini juga sejalan dengan penelitian (Lam , 2014) bahwa media pembelajaran berbasis Prezi memiliki efektivitas yang baik ketika digunakan dalam pembelajaran. Media pembelajaran berbasis Prezi mampu meningkatkan minat siswa, dan bahkan mereka lebih menikmati media Prezi daripada media Powerpoint. Namun hasil tersebut bertolak belakang dengan apa yang ditemukan oleh (Chou et al., 2015) bahwa tidak ada perbedaan yang signifikan antara media pembelajaran Prezi dengan Powerpoints. Hasil studi oleh (Dzulhijjah et al., 2015) juga menemukan bahwa pembelajaran sains menggunakan Prezi memberikan hasil belajar yang lebih signifikan dibandingkan dengan pembelajaran tradisional.

Walaupun media pembelajaran penggolongan hewan berbasis Preæi yang dikembangkan telah memenuhi kelayakan, namun beberapa aspek masih perlu dikembangkan lagi sesuai dengan hasil uji coba dengan siswa kelas 3 sekolah dasar. Aspek-aspek tersebut meliputi pemilihan warna background dan sound, ukuran kalimat, contoh-contoh soal, dan audio perlu diperbaiki. Hal ini sejalan dengan aspek visualisasi dan juga psikologi anak yang masih berada pada tahap konkrit dan semi konkrit (Piaget, 1976).

\section{SIMPULAN}

Berdasarkan analisis data yang dilakukan, maka dapat disimpulkan bahwa media pembelajaran penggolongan hewan berbasis Prezi yang dikembangkan layak digunakan dalam pembelajaran di kelas 3 sekolah dasar. Tingkat kelayakan ini ditunjukkan dari hasil validasi ahli bahasa, media, dan materi yang memberikan kategori sangat baik terhadap media Prezi yang dikembangkan. Hal yang sama juga ditunjukkan dari hasil uji coba media Prezi dengan siswa kelas 3 sekolah dasar bahwa media yang digunakan memiliki tingkat efektivitas yang amat baik untuk digunakan di sekolah dasar. Adapaun saran dari penelitian ini yaitu diharapkan penelitian selanjutnya mengembangkan beberapa aktivitas pembelajaran sains berbasis Prezi dan mengujicobakan efektivitas media pembelajaran sains berbasis Prezi, serta membandingkan dengan media-media pembelajaran lainnya. Sementara itu, guru-guru perlu didukung untuk mampu membuat media pembelajaran yang menarik menggunakan Pręi. 


\section{REFERENSI}

Anantyarta, P., \& Sholihah, F. N. (2020). Pengembangan Multimedia Pembelajaran pada Materi Bioteknologi menggunakan Program Autoplay. Journal of Natural Science and Integration, 3(1), 45-57.

Azhar, A. (2011). Media pembelajaran. PT Raja Grafindo Persada. Jakarta: T Raja Grafindo Persada.

Burhanudin, R., \& Suyoso, S. (2018). Pengembangan Media Pembelajaran Presentasi Berbasis Software Prezi Untuk Meningkatkan Motivasi dan Hasil Belajar Fisika Siswa SMA Kelas X. E-Journal Pendidikan Fisike, 7(1), 38-49.

Chou, P. N., Chang, C. C., \& Lu, P. F. (2015). Prezi versus PowerPoint: The Effects of Varied Digital Presentation Tools on Students' Learning Performance. Computers and Education, 91, 73-82. https://doi.org/10.1016/j.compedu.2015.10.020

Dzulhijjah, P. D., Noer, A. M. N., \& Linda, R. L. (2015). Penerapan Prezi Dekstop sebagai Media Presentasi untuk Meningkatkan Prestasi Belajar Siswa pada Pokok Bahasan Hidrokarbon di Kelas X SMA Negeri 9 Pekanbaru. Riau University.

Gaming, Z. (2017). Gajah lagi makan di kebun binatang. Retrieved from https://www.youtube.com/watch?v=nrLiDDq--XI

Jariati, E., \& Yenti, E. (2020). Pengembangan E-Magazine Berbasis Multipel Representasi untuk Pembelajaran Kimia di SMA pada Materi Larutan Elektrolit dan Non Elektrolit. Journal of Natural Science and Integration, 3(2), 138-150.

Lam, A. (2014). Evaluating the Effectiveness of Prezi in Higher Education. Journal of Medical Imaging and Radiation Sciences, 45(2), 174.

Liani, L., Rini, R., \& Rery, R. U. (2017). Pengembangan Media Pembelajaran Kimia Berbasis Powtoon pada Pokok Bahasan Hidrokarbon di Kelas XI SMA/Sederajat. Fakultas Keguruan dan Ilmu Pendidikan Universitas Riau. Riau University.

Mahyuddin, R. S., Wati, M., \& Misbah, M. (2017). Pengembangan Media Pembelajaran Fisika Berbasis Zoomable Presentation Berbantuan Software Prezi pada Pokok Bahasan Listrik Dinamis. Berkala Ilmiah Pendidikan Fisika, 5(2), 229-240.

Perron, B., \& Stearns, A. (2010). A Review of A Presentation Technology: Prezi.

Piaget, J. (1976). Piaget's theory. In B. Inhelder, H. H. Chipman, \& C. Zwingmann (Eds.), Piaget and His School (pp. 11-23). Springer Study Edition. Springer Berlin Heidelberg.

Putra, Z. H., Witri, G., \& Yulita, T. (2019). Development of Powerpoint-Based Learning Media in Integrated Thematic Instruction of Elementary School. International Journal of Scientific and Technology Research, 8(10), 697-702.

Rodhi, M. Y., \& Wasis, W. (2014). Pengembangan Media Pembelajara Berbasis Prezi untuk 
Meningkatkan Keterampilan Berpikir Kritis pada Materi Kalor. Inovasi Pendidikan Fisika, 3(2), 137-142.

Sanjaya, W. (2013). Strategi Pembelajaran Berorientasi Standar Proses Pendidikan. Jakarta: Kencana Prenada Media.

Settle, Q., Abrams, K. M., \& Baker, L. M. (2011). Using Prezi in the Classroom. NACTA Journal, 55(4), 105.

Sugiyono. (2014). Metode Penelitian Pendidikan: Pendekatan Kuantitatif, Kualitatif, dan R\&D. Bandung: Penerbit Alfabeta.

Sugiyono. (2019). Metode Penelitian Pendidikan. Bandung: Alfabeta.

Surani, S., \& Ampera, D. (2017). Pengembangan Media Pembelajaran Prezi pada Mata Pelajaran Membuat Pola di SMK Awal Karya Pembangunan Galang. SILUET Jurnal Pendidikan Tata Busana), 1(1).

Untari, Y. P., Kurniawan, E. S., \& Fatmaryanti, S. D. (2014). Pengembangan Media Pembelajaran Fisika Online Prezi dalam Pokok Bahasan Alat Optik pada Siswa Kelas X IPA SMA Negeri 3 Purworejo Tahun Pelajaran 2013/2014. Radiasi: Jurnal Berkala Pendidikan Fisika, 5(2), 4549.

Wahyuni, N., \& Ananda, L. J. (2021). Development of Thematic Teaching Materials Based on Discovery Learning in Elementary School. Journal of Teaching and Learning in Elementary Education, 4(1), 122-130. 